\title{
Knowledge-based supervision and control of wastewater treatment plant: a real-time implementation
}

\author{
J.A. Baeza,*E.C. Ferreira** and J . Lafuente* \\ *Departament d'Enginyeria Q uímica, Universitat A utònoma de B arcelona, 08193 B ellaterra, España \\ ${ }^{* *}$ C entro de Engenharia B iológica - IB Q F, Universidade do Minho, 4710-057 B raga, Portugal
}

\begin{abstract}
The hardware architecture and the software development of a real-time knowledge-based distributed control system for the supervision of a wastew ater treatment pilot plant are presented. The operation scheme is based on an $\mathrm{A}^{2} / 0$ system (anaerobic, anoxic, oxic) and includes organic matter removal, nitrification/denitrification, and Enhanced B iological Phosphorous Removal (EBPR). The hardware architecture involves different supervision levels, including two autonomous process computers (plant control and analysers control) and a PLC. The software architecture includes a Knowledge-B ased Expert System (KBES) as the top control system. The KBES has been developed in $\mathrm{G} 2$, an expert system development environment based on object-oriented structural design. This system is fed with data obtained from the plant monitoring (in-line, on-line and off-line data) and with actuation data of the lower control levels. Using this information, the KBES supervises the pilot plant in order to help with fault detection and plant maintenance, but also modifies setpoints and other variables of the local control level to adapt the system to the different influent conditions. The overall system has been implemented and validated at pilot scale.

Keywords Activated sludge; expert system; knowledge-based expert system (KBES); real-time; wastewater treatment
\end{abstract}

\section{Introduction}

The real-time control of wastewater treatment plants constitutes a quite complex problem due to the lack of reliable on-line instrumentation and simplicity of models used to describe the microbiological processes that take place in the bioreactors (Serra et al., 1993). The use of knowledge-based techniques has been widely proposed to improve the actual situation of these systems (Gall and Patry, 1989; Barnett et al., 1992; Ozgur and Stenstrom, 1994). This paper presents the hardware architecture and the software development and implementation of a knowledge-based distributed control system for the supervision of a wastewater treatment pilot plant (WWTPP) with biological removal of organic matter, nitrogen and phosphorus. In previous works, the main prominence was oriented to the knowledge structure development (Serra et al., 1993; Sànchez et al., 1996; Serra et al., 1997) and control strategies (Moreno et al., 1992), but the real-time implementation of the data knowledge structure is the main essence of our current work (Baeza, 1999a, 1999b).

In this development, as the main tendency in the actual real-time control and supervision of processes, all the possible knowledge and the top autonomous decision capacity at every subsystem of the process is applied. In this supervisory control outline, every element supervises elements situated hierarchically under its control. This increases the system complexity, but obtains important advantages, such as the increased control of process failure and the possibility of using the top-level control to work in the system supervision. In our case, this top-level control is occupied by a Knowledge-Based Expert System (KBES) designed in G2 (Gensym, 1995) a development environment for creating intelligent, knowledge-based, real-time applications.

\section{Methods}

The process under study is biological wastewater treatment based on $\mathrm{A}^{2} / \mathrm{O}$ multistage configuration (EPA, 1993) with nitrification-denitrification and enhanced phosphorus removal 


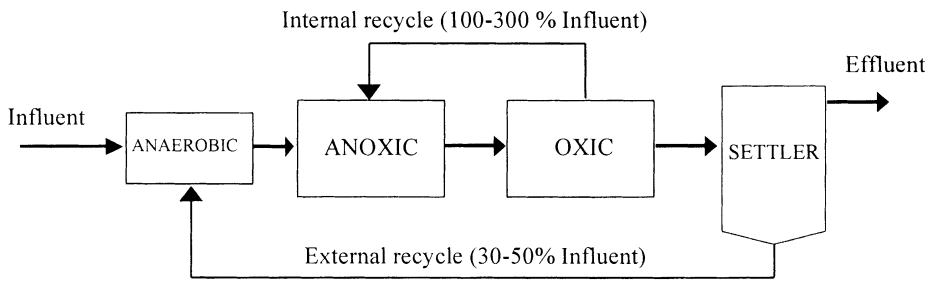

Figure $1 A^{2} / 0$ process for nutrient removal

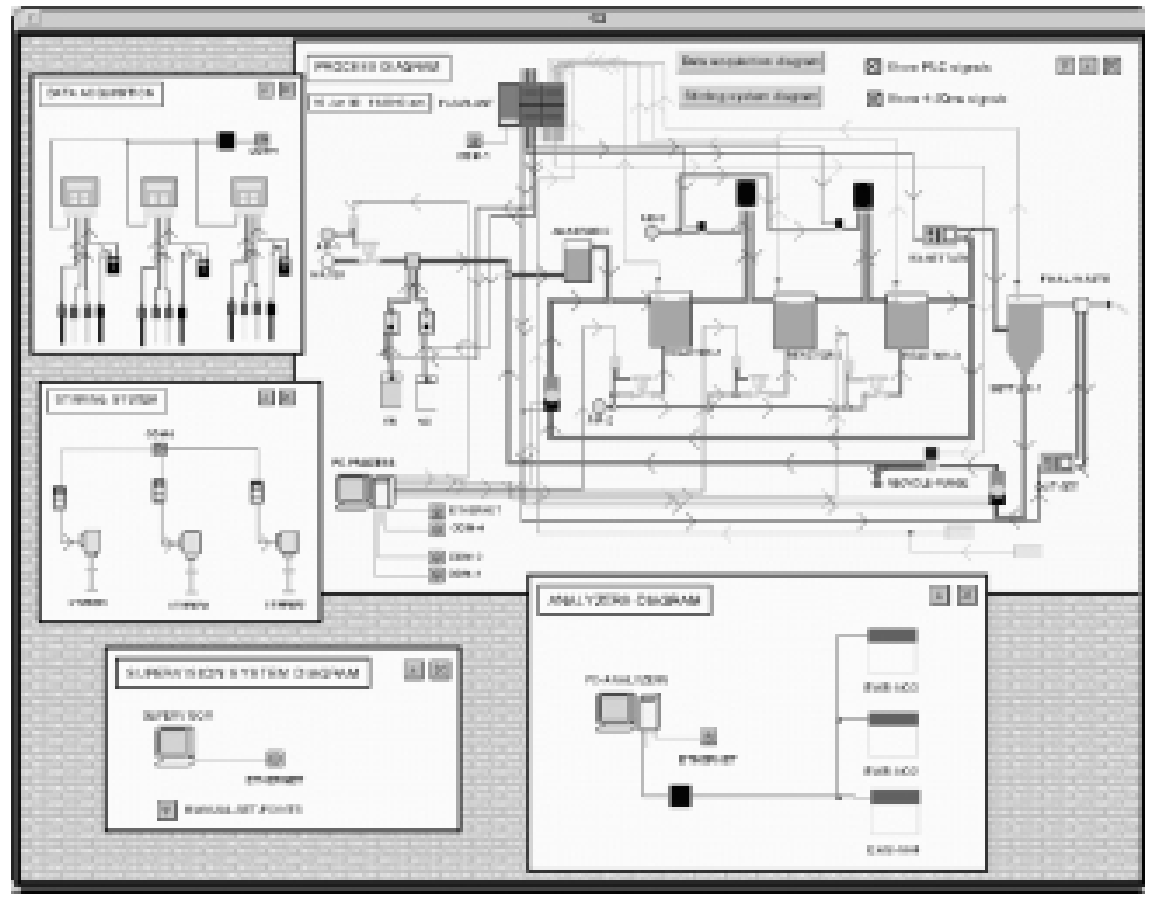

Figure 2 Process diagrams workspaces

(Figure 1). This treatment is divided into three different zones: anaerobic, anoxic and oxic. The main processes involved in this configuration are summarised next. In the oxic zone the nitrification process is carried out, and the nitrate produced in this zone is recycled with the mixed liquor to the anoxic zone (internal recycle), where the denitrification process takes place. The return sludge from the settler is recycled to the anaerobic zone (external recycle), where the influent and the sludge are mixed in anaerobic conditions. In addition, the alternation of anaerobic/oxic conditions improves phosphorus removal by means of the growing stimulation of phosphorus accumulating microorganisms.

Figure 2 shows a schematic diagram of the pilot scale facility, which consists of an anaerobic selector (9 litres), three identical aeration tanks (28 litres) and a settler (60 litres). The oxic state of these three tanks may be easily configured from the expert system, therefore the oxic and anoxic volume is variable. The first tank usually is used as an anoxic reactor, but an aerobic operation mode is also possible. The feed to the anaerobic selector is a mixture of the inlet wastewater and return sludge. The inlet wastewater is a synthetic influent made by mixing two concentrated complex sources of carbon (glucose, saccharose and starch) and nitrogen (peptone, ammonium chloride and urea) diluted with tap water. Different concentrations and flows are automatically assigned and scheduled to simulate real situations. 


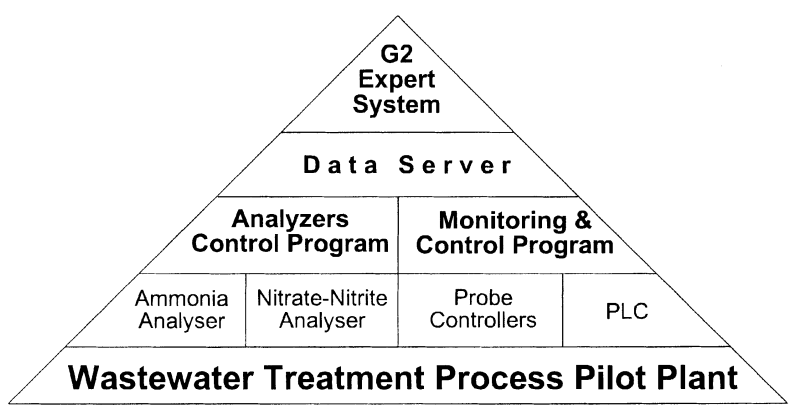

Figure 30 utline of the distributed system for supervision and control

The hardware architecture (Baeza, 1999a, 1999b) contains different supervision levels, including two autonomous process computers (plant control and analysers control) and a PLC. In the PLC program, operation failure detection and the possible corrective actions have been included. The software for the plant control computer is developed in C language, and includes graphic monitoring, data backup, PLC supervision, and control of key process parameters (DO, flow-rates, stirring rates, etc). This computer permits the control of the WWTPP with a set of prefixed setpoints, the usual level of control we can find in a WWTP. Another computer controls two on-line automatic analysers for nitrate-nitrite (Gabriel et al., 1998) and ammonia, and an automatic sampling system. Both process computers are linked via Ethernet to a data server executed in a Sun Sparcstation running Solaris operating system. This gateway is based on TCP/IP communication, and it allows the maintenance of a real time database with the information generated in every subsystem.

The KBES developed in G2 4.0 running on the Sun workstation is on the top of the system architecture. It systematises the knowledge about the process, which is based on the existing scientific knowledge and the practice acquired in our particular system. The ES acts as the master in a supervisory setpoint control (SSC) scheme. It is based on a distributed architecture integrated by a supervisor. The knowledge is organised in several modules, representing the available knowledge for every sub-process. The ES is fed with in-line data ( $\mathrm{pH}, \mathrm{T}, \mathrm{DO}, \mathrm{ORP}$, aeration and flows) and on-line data $\left(\mathrm{NO}_{3}^{-}, \mathrm{NO}_{2}^{-}\right.$and $\left.\mathrm{NH}_{4}^{+}\right)$generated by the plant using the data server. Qualitative data (odours, colours, microbiological observations data) and discrete data from off-line analyses ( $\mathrm{PO}_{4}^{3-}$, COD, TSS, VSS, TKN, and $\mathrm{SVI}$ ) can be sent to the KBES. Both the latter tasks are accomplished using the Internet as a vehicle. Each specialised operator can send specific data from any computer using a form page on the WWW. HTML code generates an e-mail formatted message using the PERL script language. The KBES is able to read these messages, and to use this symbolic and numeric knowledge to update on object's attributes. Using rules based on the available data, the expert system continuously decides the optimum control to achieve the required nitrogen and organic matter removal. Finally, control actions are transmitted to the process computers that actuate each element of the plant. The definitive scheme is outlined in Figure 3.

\section{Results and discussion}

KBES Implementation

All the KBES knowledge is structured through a whole set of rules and procedures for each subsystem of the WWTPP. Knowledge representation in G2 is maintained and extended through classes. Classes have attributes, which define the inherited and locally defined properties of the class. Main classes considered include process units (14 definitions), instrumentation (38 definitions), connections (27 definitions), sludge and microorganisms (84 definitions), and computers (4 definitions). Every object is an instance of a class, which 
is defined through an object definition. Figure 2 - the process diagrams workspaces - presents several objects with their icons and connection stubs. The workspaces are the blank pages upon which G2 permits the creation of objects. A knowledge base (a container in which a set of knowledge about real or virtual entities is collected and organised) can contain one or many workspaces. A logical hierarchy of objects and workspaces to group and organise rules and objects can be created. In our prototype, the workspaces Definitions, Process Parameters, Modules, Plant Diagrams, and Graphical Monitoring were considered as main workspaces, although the total amount was more than 200.

In the KBES (Baeza, 1999a, 1999b), a set of rules (319) and procedures (45) to help fault detection, plant maintenance, and nitrification - denitrification cycle operation was implemented and validated at pilot scale. The knowledge is organised in several modules, representing the available knowledge (the prior and the acquired experience) for every sub-process of the WWTPP. This knowledge distribution has some advantages, as for example obtaining modularity, and therefore reusability and extendibility of the system, or obtaining a system able to manage the increasing complexity of these artificial intelligence systems. All the independent modules share a common database that can be used to exchange information between them. The modules act as independent agents applying numerical algorithms and rules when the situation is normal and they are controlling a simple process parameter. These parameters are generally data driven through forward chaining when new data arrives at the real time database. When the independent modules are unable to manage a detected situation or when a complex parameter has to be calculated, the supervisor requires information to be sent to the necessary modules and deduces the correct control action to be made. The rules and procedures implemented in the main modules are described next.

In the Bioreactors Module, some rules for the supervision of the operation of these units have been established (specially the aeration, stirring and probes subsystem behaviour). The possible deactivation of local control loops, like the oxygen control, is included in this module. In the Settler Module, rules for settler supervision have been implemented. These rules mainly monitor hydraulic and microorganisms load to this unit, sludge settleability and TSS concentration in the outlet, in order to have an earlier detection of problems in the water-microorganisms separation. The Pumping System Module has rules to supervise the operation and maintenance schedule of pilot plant pumps, and is also in charge of maintaining the desired recycling conditions. It can work with different strategies, as for example, fixed flow or fixed recycling/inlet flow ratio. The Feeding System Module supervises the automatic feeding system, checking the total volume and concentration of compounds fed to the pilot plant. This module makes an estimation of the volume of concentrates used, and advises the operator when the vessel of concentrate should be filled. The COD Removal Module estimates the ratio food/microorganisms, and advises when this relation can cause problems for the plant. Some predefined usual situations, such as overload or low-load, can be detected by the implemented rules and then the programmed control actions are applied to minimise future problems. In the Nutrient Removal Module some control algorithms to improve nitrogen removal without affecting phosphorus removal are implemented. Here are included rules for the variation of the internal recycle ratio (to improve nitrate and nitrite removal), the modification of external recycle ratio (to face up to load increase) or the modification of oxygen setpoints in the three reactors (in order to obtain better nitrification rates or to minimise oxygen consumption in low-load periods). Other different modules implement rules to maintain a predefined sludge age or to monitor the microorganisms present in the sludge to detect bulking problems.

In these rules and procedures, every measure is checked using different criteria. The measures should be in a predefined band, the rate of change should not be too fast or too 


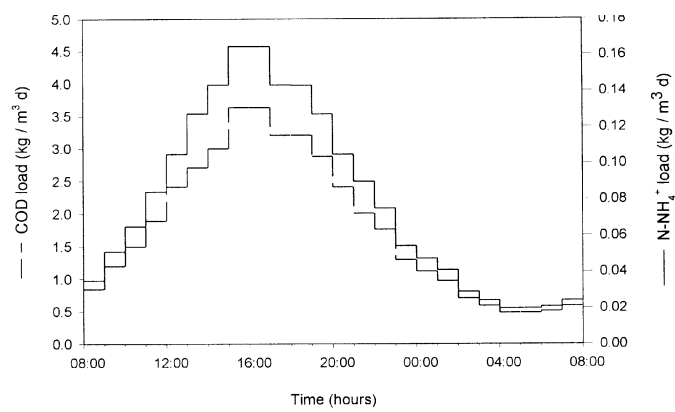

Figure $4 \mathrm{COD}$ and $\mathrm{N}-\mathrm{NH}_{4}^{+}$loads in the pilot plant

slow and the measures should not be in contradiction with other measures. If the data is considered not reliable, the KBES can deactivate local control loops and establish constant actuation, based on normal values.

\section{Experimental results}

To ensure the behaviour of the whole system, different series of experiments have been carried out. In these experiments, some strategies to improve nutrient removal, implemented by means of rules in the KBES, were checked. As an example of the strategies implemented, the internal recycle ratio variation is shown. The pilot plant was fed with a synthetic mixture made with the automatic feeding system. Different flows of $\mathrm{C}$-concentrate, $\mathrm{N}$-concentrate and tap water were assigned and scheduled to obtain the loads shown in Figure 4. These profiles emulate the situation in a real plant, with different loads during 24 hours, including a high-load period and a low-load period.

In addition to the $\mathrm{N}-\mathrm{NH}_{4}^{+}$load described in figure 4, there are other contributions to the total nitrogen introduced in the pilot plant. There is an organic nitrogen contribution due to the peptone included in the $\mathrm{N}$-concentrate, and there is also a nitrate concentration because of the tap water nitrate content. In table 1 are summarised the different contributions of the nitrogen forms to the plant influent during every 24-hour periods studied.

In order to compare the behaviour of the pilot plant, the results of two experiments are shown here. In experiment (a), the local control maintained the recycle flows in a constant prefixed ratio, but in experiment (b), the KBES modified the setpoint of internal recycle ratio to improve denitrification, based on the effluent measures acquired by the analytical subsystem. In both experiments the external recycle (sludge from the settler introduced into the anaerobic selector) was maintained at 0.5 times the inlet flow (external recycle flow= $0.5 *$ inlet flow). This recycle ratio of 0.5 has showed good results of biomass separation in previous experiments, so it was the one selected.

In reference to the internal recycle flow, the plant can work with a fixed flow. However, to achieve a better nitrate removal, a flow based on the influent flow is generally established. Although in the $\mathrm{A}^{2} / \mathrm{O}$ operation scheme it is not possible to achieve a $100 \%$ nitrate

Table 1 Total nitrogen introduced in the pilot plant during the 24 -hours periods

Integrated load of nitrogen (g/d)

\begin{tabular}{lr}
\hline $\mathrm{N}-\mathrm{NH}_{4}^{+}$ & 7.264 \\
$\mathrm{~N}-\mathrm{N}_{\text {organic }}$ & 5.049 \\
$\mathrm{~N}-\mathrm{NO}_{3}^{-}$ & 0.709 \\
$\mathrm{~N}$ total & 13.022 \\
\hline
\end{tabular}


Table 2 S etpoints of oxygen and recycle ratio in the pilot plant in experiments (a) and (b)

\begin{tabular}{|c|c|c|c|c|c|}
\hline \multirow[b]{2}{*}{ Experiment } & \multicolumn{3}{|c|}{ Oxic state (DO setpoint $\mathrm{mg} \mathrm{O}_{2} / \mathrm{I}$ ) } & \multicolumn{2}{|c|}{ Recycle ratio } \\
\hline & Reactor 1 & Reactor 2 & Reactor 3 & External & Internal \\
\hline (a) & Anoxic $(D 0=0)$ & $0 \times x i c(D O=3)$ & $0 \times x i c(D O=3)$ & 0.5 & 2 \\
\hline (b) & Anoxic $(D 0=0)$ & $0 \times x i c(D O=3)$ & $0 \times x i c(D 0=3-1)$ & 0.5 & $1-2-4$ \\
\hline
\end{tabular}

removal, it is clear that when the internal recycle ratio increases, more nitrate is recycled to the anoxic reactor. If the nitrate input increases, and there is no COD nor reaction velocity limitations the denitrification would happen to a larger extent. The limit for this recycle comes, in general, with the economy of the process.

In experiment (a), a fixed recycle ratio of 2 is maintained (recycle flow from oxic to anoxic zone is twice the influent to the pilot plant). In experiment (b) the recycle ratio is modified by the KBES depending on the concentration of nitrogen $\mathrm{N}-\mathrm{NO}_{\mathrm{x}}$ (nitrate plus nitrite) in the effluent. There are three different setpoints depending on this limit of $\mathrm{N}-\mathrm{NO}_{\mathrm{x}}$ :

$$
\begin{array}{ll}
\mathrm{N}-\mathrm{NO}_{\mathrm{x}}<0.5 \mathrm{mg} / \mathrm{l} & \mathrm{F}_{\mathrm{IR}} / \mathrm{F}_{\mathrm{I}}=1 \\
0.5 \mathrm{mg} / \mathrm{l}<\mathrm{N}-\mathrm{NO}_{\mathrm{x}}<1.5 \mathrm{mg} / \mathrm{l} & \mathrm{F}_{\mathrm{IR}} / \mathrm{F}_{\mathrm{I}}=2 \\
\mathrm{~N}-\mathrm{NO}_{\mathrm{x}}>1.5 \mathrm{mg} / \mathrm{l} & \mathrm{F}_{\mathrm{IR}} / \mathrm{F}_{\mathrm{I}}=4
\end{array}
$$

The maximum recycle ratio used was 4 , because it is the biggest that can be obtained with the recycle pump for the maximum influent flow. The minimum used was 1 , because there is always some ammonium in the influent, which will have to be nitrified and then denitrified. The medium recycle ratio used was 2 , a value which permits generally good results. This was also the fixed value used in experiment (a).

In Table 2 are shown the different setpoints that establish the conditions in every experiment. The oxic state was anoxic in reactor 1 and oxic $(3 \mathrm{mg} / \mathrm{l})$ in reactor 2 in both experiments. In reactor 3, different conditions were established, depending on the recycle ratio. In experiment (a), it was maintained with a 3-mg/l setpoint, while in experiment (b) it had two different values. When a recycle ratio of 1 or 2 was used, it was maintained with the same conditions as experiment (a) $(3 \mathrm{mg} / \mathrm{l})$. If the recycle ratio was set to 4 , the oxygen setpoint was reduced to $1 \mathrm{mg} / \mathrm{l}$, in order to minimise the oxygen input to the anoxic reactor that could interfere in the denitrification process. In previous experiments, it was shown that reducing the oxygen setpoint from 3 to $1 \mathrm{mg} / \mathrm{l}$ did not reduce considerably the nitrification in the system, nor did it increase the denitrification significantly, because of the absence of readily biodegradable COD in this third reactor.

The different setpoints are sent to the local control system, which is able to modify the corresponding variables in order to maintain those values. In reference to the recycle flows, it modifies these flows to maintain a constant ratio of flow recycle/flow influent, according to the influent flow changes.

In Figure 5 the monitoring results for effluent ammonium, nitrite and nitrate and the flows during the 24-hour period are shown. Figures 5(a) and 5(c) correspond to experiment (a) and figures 5(b) and 5(d) to experiment (b). In figures 5(c) and 5(d) the influent flow to the pilot plant (continuous lines), the internal recycle flow (dotted lines) and the external recycle flow (dashed lines) are shown. As can be seen from the figure, in the experiment (a) the external recycle flow is modified to keep the predefined recycle ratio of 0.5 , whilst the internal recycle ratio flow is varied to maintain a ratio of 2 .

As can be seen from figures 4 and 5c, the maximum load of nitrogen and COD to the pilot plant matches with the maximum of the inlet flow, at around 16:00 hours. However, if we 


\begin{tabular}{|c|c|c|c|c|c|c|c|c|c|}
\hline Experiment & $\mathrm{N}-\mathrm{NH}_{4}^{+}(\mathrm{g})$ & $\mathrm{N}-\mathrm{NO}_{3}(\mathrm{~g})$ & $\mathrm{N}-\mathrm{NO}_{2}^{-}(\mathrm{g})$ & $\mathrm{N}_{\text {TOTAL }}(\mathrm{g})$ & $\mathrm{N}$ removed $(\mathrm{g})$ & \% removal & $\% \mathrm{~N}-\mathrm{NH}_{4}^{+}$ & $\% \mathrm{~N}-\mathrm{NO}_{3}$ & $\% \mathrm{~N}-\mathrm{NO}_{2}^{-}$ \\
\hline (a) & 1.247 & 0.410 & 0.307 & 1.964 & 11.058 & 84.92 & 63.49 & 20.88 & 15.63 \\
\hline (b) & 1.239 & 0.218 & 0.284 & 1.741 & 11.281 & 86.63 & 71.17 & 12.51 & 16.31 \\
\hline
\end{tabular}

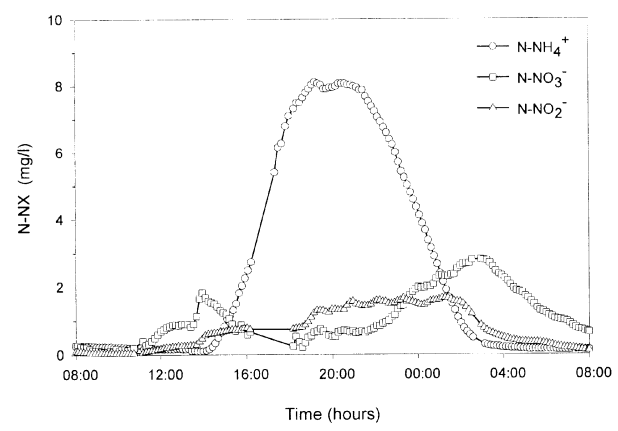

(a)

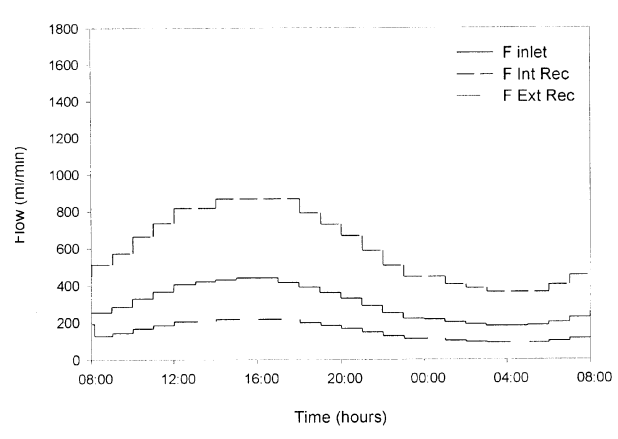

(c)

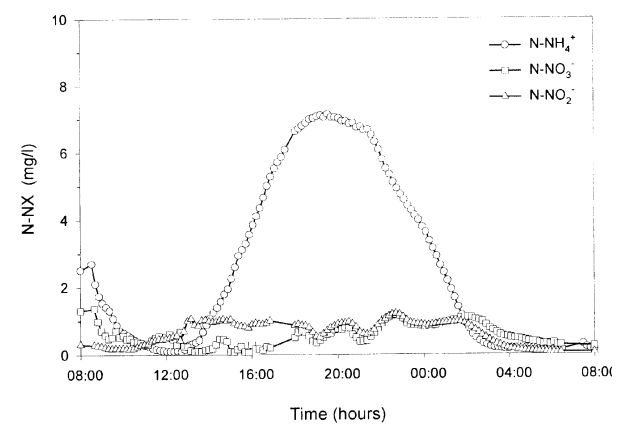

(b)

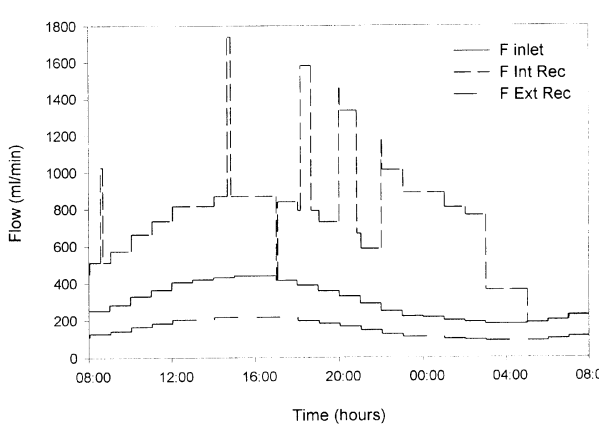

(d)

Figure 5 Effluent concentrations of nitrogen and flow variations in experiment (a) (Figures a and c) and experiment (b) (Figures $b$ and $d$ )

look to figure 5a, it can be observed that the maximum concentration of $\mathrm{N}-\mathrm{NH}_{4}^{+}$is produced around 20:00 hours. This delay is produced because of the residence time in the pilot plant (about 6 hours with the flow during this high load period). From 16:00 to 24:00 hours approximately, the pilot plant is not able to nitrify the load applied, therefore the effluent contains a high concentration of nitrogen in the form of ammonium. When the load and flow diminish, the pilot plant is able to nitrify the accumulated ammonium with the same operation conditions. This increases the nitrate and nitrite concentration in the system, however, the influent flow decreases, and the internal recycle is reduced in the same ratio. In this situation, although the flow of internal recycle is twice the inlet flow as the control system maintains, it is not enough to denitrify the nitrate and nitrite produced.

One solution to improve the situation could be to increase the internal recycle ratio setpoint. A constant ratio of 4 would help the system to denitrify all the nitrate and nitrite; on the contrary it has also its drawbacks in the economic point of view. In order to apply this recycle ratio only when it was necessary, the commented limits of the oxidised forms of nitrogen $\left(\mathrm{N}-\mathrm{NO}_{\mathrm{x}}\right)$ were implemented in the KBES. Those limits were applied in experiment (b). 
In Figures $5 \mathrm{~b}$ and $5 \mathrm{~d}$ the results of this experiment are shown. If the levels of nitrogen are compared with respect to experiment (a), a similar concentration of nitrogen as ammonium can be observed in both experiments. Comparing figures $5 \mathrm{~b}$ and $5 \mathrm{~d}$, it is possible to observe that when the total $\mathrm{N}-\mathrm{NO}_{\mathrm{x}}$ exceeds the defined setpoint of $1.5 \mathrm{mg} / \mathrm{l}$, the KBES increases the recycle ratio setpoint to 4 . As can be observed, the nitrate and nitrite concentrations are kept a lower level than in experiment (a). In addition, the KBES decreases the recycle ratio when high values are not needed anymore: around 3:00 a.m. the ratio is reduced to 2 and after 5:00 a.m. it is reduced to its minimum ratio, 1 . With these conditions, the high recycle ratios are only used when it is necessary, improving the economy of the process.

In Table 3 are summarised the different nitrogen contributions to the effluent. Firstly, the grams of the species analysed in the effluent are specified. Then, the total nitrogen, the nitrogen removed and the N-removal percentage are specified. Finally, the percentages of the species in the effluent are shown.

The removed nitrogen and the \% removal are obtained using the data from Table 1. As can be calculated from these results, there is a decrease of $30 \%$ in the nitrogen as nitrate and nitrite presented in the effluent. This percentage would have been better if more restrictive limits for $\mathrm{N}-\mathrm{NO}_{\mathrm{x}}$ had been defined, but it would have had a negative impact in the economy of the process. With respect to the total nitrogen the total amount is reduced, although the fraction of ammonium increases because of the $\mathrm{N}-\mathrm{NO}_{\mathrm{x}}$ diminution.

The ammonium nitrogen is not affected by the strategy shown, so the total amount of ammonium is almost the same in both cases. As this specie is the biggest contribution to the nitrogen in the effluent, the percentage of removal does not decrease to a great extent. To improve the ammonium removal, other strategies have been implemented (Baeza, 1999b) which permitted to reduce the total amount of nitrogen in the effluent to almost $50 \%$.

\section{Conclusions}

The main achievement of this prototype is a versatile framework able to deal with different plant configurations, based on the object-oriented paradigm and on rule-based reasoning. The on-line feature is an important innovation of this system, particularly for data monitoring and supervisor control. In our system, different control strategies can be easily implemented for activated sludge control of carbon, nitrogen, and phosphorus removal with different plant configurations. In addition, the developed KBES can be adapted to a new plant in a short time because of object-oriented design. Finally, this system is running continuously for more than 800 days. The supervisory KBES shows an excellent performance to manage the WWTPP. The developed system detects and controls wrong and special operations, as for example: pump failure, feeding problems, probes malfunction, equipment maintenance, analysers control and maintenance, etc.

\section{Acknowledgements}

This work was supported by the C.I.C.Y.T. - projects BIO94-0679-C02 and AMB97-0889c03-01. J. Baeza received a predoctoral fellowship from the C.I.R.I.T. (Generalitat de Catalunya). The Fundação Calouste Gulbenkian (Portugal) provided financial support for E.C. Ferreira through a post-doctoral research grant.

\section{References}

Baeza, J., Gabriel, D. and Lafuente, J. (1999a). An expert supervisory system for a pilot WWTP. Environmental Modelling \& Software 14, 383-390.

Baeza, J. (1999b). Development and Implementation of a Supervisory System for the Management and Control of WWTP. (In Spanish). PhD thesis, Department of Chemical Engineering, Universitat Autònoma de Barcelona. 
Barnett, M.W., Patry, G.G. and Hiraoka, M. (1992). Knowledge-based (expert) systems for the activated sludge process. Dynamics and Control of the Activated Sludge Process, J.F. Andrews (ed.), Technomic Publ. Co., Lancaster, pp. 231-243.

EPA Manual of Nitrogen Control. (1993). EPA/625/R-93/010 U.S. Environmental Protection Agency. Washington, U.S.A.

Gabriel, D., Baeza, J., Valero, F. and Lafuente, J. (1998). A novel FIA configuration for the simultaneous determination of nitrate and nitrite and its use for monitoring an urban waste water treatment plant based on n/d criteria. Anal. Chim. Acta., 359, 173-183.

Gall, R.A.B. and Patry, G.G. (1989). Knowledge-based system for the diagnosis of an activated sludge plant. Dynamic Modeling and Expert Systems in Wastewater Engineering, G.G. Patry and D. Chapman (eds.), Lewis Publ., Chelsea, pp. 193-240.

Gensym G2 Reference Manual Version 4.0. (1995). Gensym Corporation, Cambridge, MA, USA.

Moreno, R.C., De Prada, C., Lafuente, J., Poch, M. and Montagu, G. (1992). Non-linear predictive control of dissolved oxygen in the activated sludge process. Modelling and Control of Biotechnological Processes, M.N. Karim and G. Stephanopoulos (eds.), Pergamon Press, Oxford, UK, pp. 289-293.

Ozgur, N.H. and Stenstrom, M.K. (1994). KBES for process control of nitrification in activated sludge process. J. of Environ. Eng., 120(1), 87-107.

Sànchez, M., Cortés, U., Lafuente, J., Roda, I.R. and Poch, M. (1996). DAI-DEPUR: An integrated and distributed architecture for wastewater treatment treatment plants supervision. Artificial Intelligence in Engineering, 1, 275-285.

Serra, P., Lafuente, J., Moreno, R., De Prada, C. and Poch, M. (1993). Development of a real time expert system for wastewater treatment plants control. Control Eng. Practice, 1(2), 329-335.

Serra, P., Sanchez, M., Lafuente, J., Cortes, U. and Poch, M. (1997). ISCWAP: A knowledge-based system for supervising activated sludge processes. Computers Chem. Engng., 21(2), 211-221. 
